\title{
SPATIAL SELECTION OF HERITAGE AND TRANSFER OF LOCAL IDENTITY: A DUAL CASE STUDY BASED ON TWO HISTORICAL AND CULTURAL DISTRICTS IN CITY F, CHINA
}

\author{
H. Wang ${ }^{1}$, Y. Zhang ${ }^{2 *}$ \\ ${ }^{1}$ School of Social and Behavioural Sciences, Nanjing University, China - 233316307@qq.com \\ ${ }^{2}$ Bielefeld Graduate School in History and Sociology, Bielefeld University, Bielefeld, Germany - yiming.zhang@uni-bielefeld.de
}

KEY WORDS: Heritage spaces, Historic and cultural districts, Identity transfer, Local identity, National identity, Government selection, Aborigines' struggle

\begin{abstract}
:
By comparing the successive development, government planning, and public expectations of two landmark historical and cultural districts in F city, this paper attempts to explore the state's selection and cultural setting of heritage spaces, as well as the identity transfer of local residents in individual memory and collective creation. With case studies on historical districts of $\mathrm{S}$ and $\mathrm{Y}$ neighborhoods, this paper argues that the selection of heritage spaces is actually a borrowing of local history and culture by the state's modernization tendency. With the extinction/reformation of the medium of identity, the aborigines struggle with disappearance of their place and the affirmation of heritage, eventually extending the boundaries of the meaning of "place" and shifting local identity to national and ethnic identity.
\end{abstract}

\section{INTRODUCTION}

\subsection{Background}

In the past decade, culture has been exploited in a big way as a potential value-added asset in urban and rural China (He et al., 2017). As a physical record of historical and cultural development stages, architectural heritage is naturally included in the top of urban cultural development. Under the ideological guideline of "culture on stage, economy singing", a large number of historical and cultural districts, historical museums, cultural and creative parks, and special cultural towns are scattered across the country, and the cultural tourism industry provides an alternative way for governments and enterprises to make money. At the same time, under the cultural tourism industry's transformation of ancient architectural forms and overall appearance, a large number of indigenous people have become demolished households, and traditional neighbourhoods have become retro shopping streets, appearing as signs of redevelopment of traditional resources.

The $\mathrm{S}$ and $\mathrm{Y}$ districts discussed in this paper are both historical and cultural districts that have been developed in recent years in $\mathrm{F}$ city. Among them, the S district, with its Ming and Qing dynasty architectural complexes as its prominent feature, was selected as one of the first batch of "China's Ten Famous Historical and Cultural Streets"; since 2015, the S district has been listed as one of the thirty Chinese historical and cultural districts, and won the UNESCO Asia-Pacific Cultural Heritage Conservation Award. The F district, with its modern Westernstyle architectural heritage, has been developed and protected since 2010, and was listed as a national cultural heritage protection unit in 2013.

\subsection{Research Question}

There are lots of discussions on the impact of the development of heritage spaces on indigenous people (Sun and Zhou 2015, Herzfeld 2016), but rare of them elaborate subtle changes of indigenous local identity in the formation mechanism of heritage space and its transformation process (some could be found in: Chan and Lee 2017, Lin 2013).

Focusing on formation and transformation process of heritage spaces as well as changes of indigenous local identity, this research has two questions: 1) What kind of material culture space can be a heritage space; 2) How the national significance of heritage space affects the meaning of indigenous life.

\subsection{Result}

This paper argues that the selection of heritage spaces is actually a borrowing of local history and culture by the modernizing tendencies of the state. Through the spatialization and heritagization of traditional Chinese culture, we argue that the initial positioning of heritage spaces gradually moves towards a different future with the intervention of a series of factors such as commercial capital, political goals, and modernization requirements. In this process, heritage spaces increasingly become a hybrid and wrestling ground between global values, power discourse and local culture, and their difference from other surrounding spaces reflects the fragmentation and alienation of the local environment by the process of heritagization.

With the extinction/reformation of identity media, indigenous people struggle with the disappearance of their place of origin and the affirmation of their heritage, eventually stretching the

\footnotetext{
* Corresponding author
} 
boundaries of the meaning of "place" and shifting local identity to national identity. The relocated or soon-to-be-relocated aborigines who are the focus of this paper are often the ones who choose to compromise with authority. Their compromise is not a passive concession, but rather, as part of the global heritage conservation movement, they have integrated their local identity into their national identity, and into the political environment where "Chinese culture" is in close communication and competition with global culture. This weakens the physical boundaries of place and incorporates it into the political and cultural imagination of heritage. Emotionally, they may question and even criticize the heritage and modernization of places due to the loss of meaning in their personal lives, but they never deny the national cultural representation and global competitiveness of the place as a heritage space. This transfer of identity has, to some extent, become an important path for indigenous people to alleviate the dislocation of local identity.

\section{METHODOLOGY}

From April to July 2020, I (the first author) visited the F city archives several times to check the relevant historical materials, collect local history materials. I also visited the $\mathrm{S}$ and $\mathrm{Y}$ districts to observe the architectural style and pedestrians, and contacted relevant government agencies, enterprises and individuals, and carried out semi-interviews with 14 people for at least 90 minutes (see Table 1 for details).

\begin{tabular}{|c|c|c|c|c|}
\hline No. & Participants & Gender & DOB & Identity \\
\hline 1 & $\mathrm{XZ}$ & $\mathrm{F}$ & 1985 & Narrator of S \\
\hline 2 & LJF & M & 1949 & $\begin{array}{l}\text { Relocated Aborigine } \\
\text { of } \mathrm{S}\end{array}$ \\
\hline 3 & LJZ & M & 1978 & $\begin{array}{c}\text { Relocated Aborigine } \\
\text { of } \mathrm{S}\end{array}$ \\
\hline 4 & XX & $\mathrm{F}$ & 1985 & $\begin{array}{c}\text { Relocated Aborigine } \\
\text { of S }\end{array}$ \\
\hline 5 & LF & M & 1949 & $\begin{array}{c}\text { Relocated Aborigine } \\
\text { of S }\end{array}$ \\
\hline 6 & LQ & $\mathrm{F}$ & 1954 & $\begin{array}{c}\text { Relocated Aborigine } \\
\text { of S }\end{array}$ \\
\hline 7 & GG & M & 1965 & $\begin{array}{l}\text { Aborigine and Tea } \\
\text { Shop Owner of S }\end{array}$ \\
\hline 8 & $\mathrm{DZ}$ & M & 1988 & $\begin{array}{l}\text { Historic Landscape } \\
\text { Cultural and Creative } \\
\text { Designer of F city }\end{array}$ \\
\hline 9 & DLN & M & 1985 & Official of Y \\
\hline 10 & $\mathrm{XJ}$ & M & 1988 & Official of $Y$ \\
\hline 11 & LM & $\mathrm{F}$ & 1960 & Aborigine of $Y$ \\
\hline 12 & LV & $\mathrm{F}$ & 1990 & $\begin{array}{l}\text { Aborigine of } Y \\
\text { (married out) }\end{array}$ \\
\hline 13 & $\mathrm{DL}$ & $\mathrm{M}$ & 1986 & Aborigine of $\mathrm{Y}$ \\
\hline 14 & $\mathrm{HH}$ & $\mathrm{F}$ & 1978 & Café Owner of Y \\
\hline
\end{tabular}

Table 1. Information of participants (Anonymized).

Applying dual cases, we have innovatively compared two sites with similar development trajectories but vastly different development directions. By observing and comparing their successive development, government planning and people's expectations, we can more clearly understand the selection and cultural setting of heritage spaces by the state, as well as the identity reset of local residents in individual memory and collective creation.

\section{ANALYSIS AND CONCLUSION}

\subsection{Framework}

Local identity can usually be regarded as actors' confirmation of self (subject) identity in a specific geographical environment (Lin, 2013). Accordingly, Sun and Zhou (2015) pointed out that one important aspect of the original intention of heritage recognition is to strengthen the identity of heritage holders and avoid the marginalization of local people in local expression by protecting endangered heritage. On the other hand, as a cultural means, it transforms the heritage space into a nationalist center to avoid the marginalization of the local in the national and even the world pattern (Sun and Zhou, 2015).

However, in the practice of heritage, this original intention has been seriously impacted. State power, global standards and economic drive are the core of the construction of heritage space. On the contrary, aborigines' needs and local discourse hardly play a role (Herzfeld, 2014).

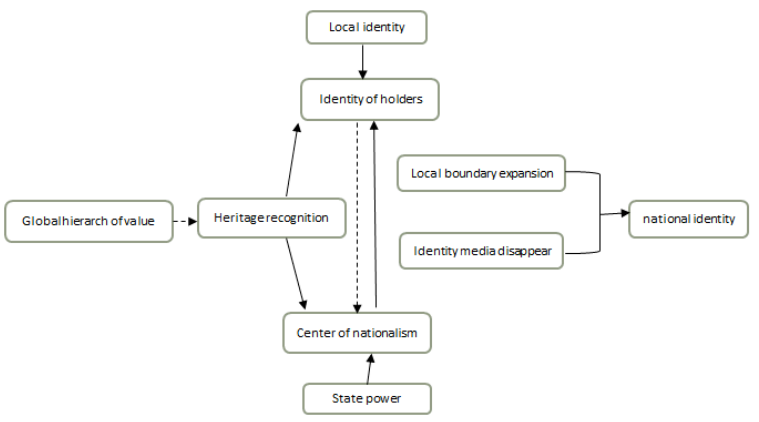

Figure 1. The impact mechanism framework of heritage recognition and heritage identity.

According to these theoretical concepts, we have established the impact mechanism framework of heritage recognition and heritage identity (see figure 1 for details). We believe that global hierarchy of value has long been accepted as the unified standard for heritage recognition, which not only makes the holders tend to learn from the "west", but also affects the center of nationalism to become an exhibition space for outsiders, rather than a place rooted in local culture and daily life. In this mechanism, identity of holders is associated with local identity, and its impact on state power is very limited. However, through the demolition and transformation of heritage space and the relocation of aborigines, state power has expanded the local boundary and plunged aborigines into an identity dislocation.

\subsection{Political considerations of heritage space selection}

3.2.1 Modernity of Chinese heritage space: Most of the selected cities and landscapes are closely related to local Chinese culture and have great potential for modernization. Spaces without modernization potential are difficult to be selected as landmark heritage conservation objects.

"The house in $Y$ is at most a scenic spot and an embassy. If you really want to dig out the cultural deposits, there is no cultural deposits. $S$ has cultural deposits. After all, there are some squares[fang] and alleys[xiang]. There used to be something with cultural deposits there." (DL, Aborigine of Y) 
Although the relevant government agencies in $\mathrm{Y}$ try to create an inclusive, integrated and diversified concept of cultural exchange between China and the west, the west has long been simplified into a single culture contrary to Chinese characteristics, which is difficult to be given new meaning and therefore difficult to be widely recognized (Goh, 2012, 2014). On the contrary, due to the differences in people's deeds, folklore, heritage artistry and cultural closeness in different regions, the differences and diversity of traditional culture are seen by more people, which is more valued and easier to stimulate the sense of national identity. Therefore, the heritage space based on traditional culture is easier to become the first choice in the heritage protection of local governments.

3.2.2 Rational Resource Deployment: From the perspective of spatial function, the construction of heritage space needs to balance the overall layout of cultural development in the province and city. The early development of Gulangyu (鼓浪屿) has caused certain restrictions on the conservation of $\mathrm{Y}$ district, while the Ming and Qing Dynasty buildings in S district have cultural uniqueness in F city and even the whole province.

"In fact, culture in $Y$ is richer than Gulangyu, but we develop later than them, and $Y$ is not like Gulangyu which is famous abroad. This is related to the geographical location of $Y$ in $F$ City, which itself is in the concept of the whole F City. The government can only concentrate resources on one thing for a period of time, and resources are always limited." (DLN, Official of Y)

Of course, the modern attributes of urban planning and spatial development give the colonial architectural heritage an opportunity. Because through the introduction of foreign / western culture, the historical depth of Chinese traditional culture is inversely set off, which not only shows the cultural inclusiveness of the combination of the West and the west, but also reflects the sense of superiority of Chinese traditional culture. In my opinion, this is not a combination of western culture, but to strengthen people's national identity by strengthening the differences between Chinese and Western culture. Specific to F City, it is manifested in the general recognition of $\mathrm{S}$ and the relative neglect of $\mathrm{Y}$.

3.2.3 Conclusion: The selected historical heritage space regained symbolic significance under the endorsement of political rights, became the representative of the National Central Culture recognized by local residents, and stimulated aborigines' national pride with traditional culture as the background. On the contrary, the shelved historical space has become the object of "demolition" and gradually disappeared from people's vision and memory.

In addition, the choice of heritage space is actually the borrowing of local history and culture by the trend of national modernization. In this process, heritage space has increasingly become a mixture and wrestling field of global values, power discourse and local culture. Its difference from other surrounding spaces reflects the division and alienation of local environment in the process of heritage.

\subsection{The demise of the identity mediator and the expansion of local boundaries}

3.3.1 Trust in government and slamming of enterprises: Market push and policy acquiescence have dismembered the living space of the aborigines, who have chosen to trust the government and scandalize corporations in the process of scattering and resettlement. This reflects the active role of the government in the process of local spatial heritagization.

The demolition and construction of $\mathrm{S}$ is divided into two stages. The first stage is led by real estate enterprises and the second stage is led by the government. The aborigines in S generally hold a negative attitude towards the first stage, believing that a well-known rich businessman who borrows government money for development is the one who "wants everything for nothing". In fact, at that time, the government was in financial shortage, failed to provide loans to a well-known rich businessman, and did not complete all the land levelling work before the building was built, resulting in that the enterprise finally completed the reconstruction of only a small part of the space. This act of pushing down the uncompleted end of the reconstruction plan and project was regarded by the people as a "heartless" capitalist, which was completely rejected. In the second stage, the real estate enterprises withdrew, and the government established the demolition office to promote relevant work.

\begin{abstract}
"We can only trust the government, or who do you trust? Well known rich businessmen come to demolish us. How can we bargain with him about demolition? In the end, the state is still responsible. For example, how to build it later? We now think that the second stage is well done. If it is taken away by wellknown rich businessmen, it will be over. The result is completely different." (LF, Relocated Aborigine of S)
\end{abstract}

In the preparation process of space heritage, real estate enterprises have become the object of prominent contradictions with the people, and local governments are hidden behind. As the media of local identity, the representational space will be demolished and rebuilt, which has a strong emotional impact on the aborigines. At the same time, local governments and major news media publicized and reported the s block protection and restoration project as a key project of urban modernization with historical significance. They stressed that demolition is a winwin situation, which not only achieved the political performance of urban development, but also improved the living environment of residents living in dilapidated and old houses. It can be said that aborigines struggle with the pull of personal local identity and external de-emotional discipline. Under the circumstances of market promotion and policy acquiescence, a large number of dismemberment of living space disintegrated the geographical media of indigenous local identity, and their close social connection gradually collapsed as they were scattered to various resettlement houses. It can be said that the heritage process, as a construction process of modern society, reshapes the traditional meaning.

In the early stage of vacating and relocation, aborigines like LF promoted the projects of real estate enterprises, resulting in ordinary people's expectations for the heritage production of the right subject, but they were angry with the taste of the project "We believe that the second stage is well done," which is not only the recognition of the heritage protection planning direction of S after the government's acceptance, but also the affirmation of the government's resettlement policy. This implies the "political trust" and "entrepreneur distrust" of the people, and also shows the positive role of the government's 
participation in heritage protection and transformation in extending the boundary of "local" and transferring local identity to national identity.

3.3.2 Paradox of housing concept: Many aborigines are caught in the contradiction of being tied to the cultural imagery of their ancestral houses on the one hand, and believing that old houses are a great safety hazard on the other. From traditional living space to modern commercial housing, the social relations of aborigines are gradually loosened, and the heritage of traditional space becomes a nationalistic practice of de-localization. Local identity of aborigines has gradually become abstracted from their concrete living practices, and has become a kind of distant memory and identification with the national heritage construction for the world in the modern era.

"I have my own opinion. It's inconvenient for me to live here alone. What if I fall upstairs and downstairs? What if you (my children) can't come in when you are ill? What can I do with so many white ants in summer? And the house is so big that I clean it alone? This will kill me! I don't regret selling the house at all, not at all (LV blamed: you didn't hesitate)." (LM, Aborigine of Y)

"No. 2 is our ancestral house. At that time, everyone was in pain when selling the house. I got married in 2004. Up to now, I still dream in this room. I often dream of all my family members, including my own childhood, or my family's deceased father or others. All the scenes in my dream are here without exception. I think I miss it more than my mother. I don't know if you will do the same. My husband and I will be nostalgic for old things." (LV, Aborigine of $\mathrm{Y}$ )

The contradiction between LM (mother) and LV (daughter) is somewhat abnormal for us. Usually, we think that the elderly is more nostalgic than the young, and are more reluctant to move away from the old community. However, the elderly LM not only sold the old foreign house, but also looked forward to the current residence being expropriated by the government. LM claims that she has no nostalgia for the old foreign house, and its housing structure and material are not conducive to her current solitary life. Although she has lived here since she married the L family, she is unwilling to give up her pursuit of current life because of nostalgia for the past, a more modern and convenient pursuit. In contrast, LV, who has been married and moved into a modern house, has deep feelings for the No. 2 foreign house in Y. She was born, married and even confinement in childbirth [zuoyuezi] here. In her mind, the house that had been sold was the place where they lived for generations and the place she dreamed of. Therefore, she always did not understand and complained about her mother. The contradiction between mother and daughter about ancestral house identity reflects the gap between emotion and practice. Although LV often goes back to her ancestral house in her dream, she has visited her mother in Y only a few times in real life, and she has not made substantive efforts to keep her ancestral house. In addition, although LM expected the inheritance of her current residence so as to obtain the opportunity of resettlement and relocation into modern housing, she did not imagine and calculate the possible relocation in the future, but was very satisfied with the location conditions of her current residence. Relatively speaking, the only thing that made her sad was the departure of her children and poor care, which was the reason why she made up her mind to sell the old foreign house.
The cultural image and potential safety hazard of ancestral house are the common digestion of local identity media in the process of heritage and urbanization. On the one hand, through the demolition and transformation of ancestral houses, the material medium of indigenous local identity was destroyed; On the other hand, through the publicity and policy support for new urban houses, a new type of community relationship has been created, weakening the emotional attachment and living intention of aborigines to their original place of residence. According to the government officials of $\mathrm{Y}, \mathrm{Y}$ has been carrying out heritage protection since 2010 . At present, more than 90 expropriation works have been completed. For the collection work, the most difficult thing is not that the aborigines refuse to sign the contract based on some kind of ancestral house identity. On the contrary, since most of the foreign houses in $\mathrm{Y}$ are government public houses, almost all of their residents live in the same foreign house intensively, providing them with resettlement houses and demolition compensation is the biggest difficulty. It can be seen that the awareness of "Insecurity" of traditional living space opposes the modern houses representing progress and the old houses representing backwardness. The pursuit of modernity also makes the aborigines choose to run away despite their love. From traditional living space to modern commercial housing, the social relations of Aborigines are gradually loose, and the heritage of traditional space has become a de-local nationalist practice. The aboriginal recognition of the original place of residence has gradually separated from the specific life practice and began to be abstracted, becoming a recognition of the distant memory and the world-oriented national heritage construction in the modern period.

3.3.3 Changes in the fabric of everyday life: Local life are expressed in the form of tourism and sightseeing, which becomes an externalized exhibition. The modernized heritage space has erased the local character and become an altruistic exhibition space. Instead of feeling that their lives are getting better, the indigenous people who remain begin to engage in a long-term bargaining with the local government in order to obtain better resettlement conditions. At the same time, they almost share the vision of making Chinese culture stand in the world through heritage spaces, and even consider it worthwhile to sacrifice their personal feelings for the place as a prerequisite for the grand cultural narrative of the nation.

"Road here used to be curved. According to the original Feng Shui, these radians let the wind blow in and will not blow away at once. They can gather money. Now the whole is straightened, the sun comes out and the feng shui is destroyed. We also liked the architectural style at that time. It was crooked and a little like an ancient house. Now it's taken right. It must pay attention to the appearance. It's much the same. I love the previous one. We lived here since childhood. We understand." (GG, Aborigine and Tea Shop Owner of S)

Compared with Y, local people although have a stronger sense of identity with $\mathrm{S}$, now $\mathrm{S}$ is more like a designed modern scenic spot than the place of residence. GG has always lived in a courtyard in $\mathrm{S}$, and his residence is only a few minutes away from his store on main street. He would go home for a nap at noon every day. Although the main street became increasingly noisy with the increase of tourists, he could not hear a sound during his nap due to the high wall courtyard of traditional folk houses. For him, although there are not many neighbourhoods in $\mathrm{S}$ now, one or two of the remaining more than 20 households are his old friends. They drink tea and talk together from time to time. As a native of F City, GG also has many friends and is not 
lonely because of the sharp decline of residents here. But sometimes on the way to the shop, looking at the straight streets, he will suddenly feel in a trance. He didn't care, and soon threw himself into his work. The construction of heritage space not only changed the relationship between aborigines and the space, but also completely changed the social life structure in the space. The vitality of local life [yanhuo qi] are expressed in the form of tourism, which has become an externalized performance.

“Some people who haven't moved now regret it. It's better to move away early. Why do I say that? Because $S$ is now full of tourism, government management, good security and good security. There is no problem. But it's TOO quiet at night. When I didn't move away, there were so many people, because it was a private house. Now there are only one or two households over there. It's quiet at night. After the travel time passed, the shop closed and there was no one left, leaving only the security guard. Unlike before, our $S$ was very busy. Now everyone is quiet." (LQ, Relocated Aborigine of S)

Some people who have moved away from $\mathrm{S}$ are less and less revisiting their hometown, because they always feel lonely. LQ was glad that she had decided to move out of $\mathrm{S}$, and looked proudly at LF, who sat beside her dejected. As a national key historical and cultural district facing the country and the world, $\mathrm{S}$ has been modernized in terms of hardware facilities, catering hygiene and cultural environment. However, this modern heritage space has obliterated the locality and become an altruistic performance space. The remaining aborigines did not feel that their lives were getting better and better, but began to play a long-term game with the local government in order to obtain better resettlement conditions. It can be said that under the joint action of tourism economy and heritage, the physical media of indigenous local identity has existed in name only.

As a heritage protector, $\mathrm{HH}$ also believes that $\mathrm{S}$ has become a "ghost district". Through HH's positive expression of the multi vitality of $\mathrm{Y}$ in recent years, it is not difficult to see that the "district culture" in her mind is the multi-cultural block under the common time of multi subjects pointed out by Zukin (1993) and other scholars. However, due to the start of $\mathrm{Y}$ heritage project, $\mathrm{HH}$ will evacuate from here. It is easy for us to see the contradiction between ancient architecture lovers and protectors like her through HH's expression. On the one hand, they hope to explore and publicize the cultural significance of historical buildings, try to make the authority see the value of historical space, and rejoice for the right to protect and register historical buildings. On the other hand, they have participated in the heritage practice by means of the government's authority in marking key heritage. When they finally attract the government's overall intervention and carry out the global heritage as usual, they feel cold about the overall destruction of traditional districts. It can be said that both the aborigines like LF and LQ in S and HH who is about to leave Y express their helplessness and even fear of the changes of the historical environment.

3.3.4 Conclusion: Generally speaking, in the process of heritage dispelling the local identity media, aboriginal cognition of housing space is impacted seriously. In addition, the construction of heritage space has not only changed the relationship between aborigines and space, but also completely changed the social life structure in the space. The local living space is replaced by the heritage tourism function, which obliterates the locality and makes the heritage space become an altruistic exhibition space. However, although there are disputes over the way of heritage protection, natives almost share the beautiful vision of making Chinese culture based on the forest of the world through heritage space, and even regard the sacrifice of personal feelings for the place as a prerequisite for the grand national cultural narrative, which is worth it.

\section{REFERENCES}

Chan, Y.W., Lee, V.P.Y., 2017. Postcolonial cultural governance: a study of heritage management in post-1997 Hong Kong, International Journal of Heritage Studies, 23(3), 275287. DOI: $10.1080 / 13527258.2016 .1269238$

Goh, D.P.S., 2012. Urban aspirations and Asian cosmopolitanisms. Geoforum, 43,1-3.

Goh, D.P.S., 2014. Between History and Heritage: PostColonialism, Globalisation, and the Remaking of Malacca, Penang, and Singapore. Trans-Regional and National Studies of Southeast Asia, 2,79-101.

He, S.J., Qian, J.X., 2017. From an emerging market to a multifaceted urban society: Urban China studies, Urban Studies, 54(virtual section).

Hsing, Y.T., 2010. The Great Urban Transformation: Politics of Land and Property in China. New York: Oxford University Press Inc.

Herzfeld, M., 2014. Heritage and corruption: the two faces of the nation-state. International Journal of Heritage Studies, 21(6), 1-14.

Herzfeld, M., 2016. Siege of the Spirits: Community and Polity in Bangkok. International Journal of Heritage Studies, 23(4), 12.

Liu, C.H., 2016. “被再造”的中国大运河: 遗产话语背景下的 地方历史、文化符号与国家权力. Cultural Heritage, 6, 60$67+158$

Lin, G., 2013. 地方认同与规划中的权力建构一一基于规划 选址的案例分析. City Planning Review, 37(5), 35-41+66.

Moustakis, C., 1990. Heuristic Research Design, Methodology, and Applications. Newbury Park: Sage.

Sun, J.X., Zhou, Y., 2015. 遗产旅游地居民的地方认同一一 “碉乡”符号、记忆与空间. Geographical Research, 34(12), 2381-2394.

Zukin, S., 1993. Landscape of Power: From Detroit to Disney World. University of California Press. 